\title{
Evaluation of high-resolution simulations of daily-scale temperature and precipitation over the United States
}

\author{
Megan D. Walker · Noah S. Diffenbaugh
}

Received: 30 June 2008/ Accepted: 2 June 2009/Published online: 30 June 2009

(c) The Author(s) 2009. This article is published with open access at Springerlink.com

\begin{abstract}
Extreme climate events have been increasing over much of the world, and dynamical models predict further increases in response to enhanced greenhouse forcing. We examine the ability of a high-resolution nested climate model, RegCM3, to capture the statistics of dailyscale temperature and precipitation events over the conterminous United States, using observational and reanalysis data for comparison. Our analyses reveal that RegCM3 captures the pattern of mean, interannual variability, and trend in the tails of the daily temperature and precipitation distributions. However, consistent biases do exist, including wet biases in the topographically-complex regions of the western United States and hot biases in the southern and central United States. The biases in heavy precipitation in the western United States are associated with excessively strong surface and low-level winds. The biases in daily-scale temperature and precipitation in the southcentral United States are at least partially driven by biases in circulation and moisture fields. Further, the areas of agreement and disagreement with the observational data are not intuitive from analyzing the simulated mean seasonal temperature and precipitation fields alone. Our evaluation should enable more informed application and improvement of high-resolution climate models for the study of future changes in socially- and economically-relevant temperature and precipitation events.
\end{abstract}

\footnotetext{
M. D. Walker · N. S. Diffenbaugh ( $\square)$

Purdue Climate Change Research Center and Department of Earth and Atmospheric Sciences, Purdue University, 550 Stadium Mall Drive, West Lafayette, IN 47907-2051, USA

e-mail: diffenbaugh@purdue.edu
}

\section{Introduction}

Extreme weather events-such as heat waves, severe daily temperatures, and severe precipitation episodes-can substantially impact physical infrastructure (e.g. Brody et al. 2007; Penning-Rowsell and Wilson 2006), human health (e.g. Gosling et al. 2007; Poumadere et al. 2005), agricultural production (e.g. Ferris et al. 1998; Lobell 2007; White et al. 2006), and energy supply and demand (e.g. Smoyer-Tomic et al. 2003). Such events are responsible for billions of dollars in economic damage, thousands of injuries, and hundreds of deaths annually in the United States alone (e.g. Easterling et al. 2000; Kunkel et al. 1999; Parry et al. 2007). Extreme temperature and precipitation regimes have been changing in recent decades (e.g. Christidis et al. 2005; Easterling et al. 2000; Karl and Knight 1998; Parry et al. 2007). For instance, in the United States, the occurrence of hot events has generally increased, while the occurrence of cold events has generally decreased (e.g. DeGaetano and Allen 2002; Easterling et al. 2000; Karl and Knight 1998; Kharin and Zwiers 2000; Meehl et al. 2005). Likewise, the fraction of total precipitation contributed by the wet tail of the daily precipitation distribution has been increasing in the United States (e.g. Easterling et al. 1999, 2000; Groisman et al. 2005).

Dynamical models consistently project further changes in the tails of the daily temperature and precipitation distributions in response to enhanced greenhouse gas forcing (e.g. Diffenbaugh et al. 2007, 2005; IPCC 2007; Schar et al. 2004). Such a response is expected on a theoretical basis (e.g. Meehl et al. 2000; Trenberth 1999), with relatively small changes in long-term mean quantities resulting in much larger shifts in the frequency and intensity of events currently occurring in the tails of the distribution 
(Diffenbaugh et al. 2007; Katz and Brown 1992; Mearns et al. 1984). Likewise, higher order statistics suggest that changes in the extremes of the precipitation distribution could be distinctly different from changes in the mean (Wehner 2004).

The prospect of future changes in extreme climate regimes demands thorough evaluation of the ability of climate models to capture the structure and dynamics of extreme temperature and precipitation events (e.g. Hegerl et al. 2006). This evaluation is particularly urgent given that climate model biases can affect simulated climate changes (Hall et al. 2008). To date, most of the evaluation of simulated daily-scale events has been directed towards relatively low resolution general circulation models (GCMs) (e.g. Huth et al. 2000; Kysely 2002). Much less work has been devoted to assessing the performance and sources of errors in high-resolution climate models (despite notable exceptions, including Bell et al. (2004), Duffy et al. (2003), Koffi and Koffi (2008). Given that fine-scale climate processes have been shown to regulate the response of the tails of the daily-scale temperature and precipitation distributions (e.g. Bell et al. 2004; Christensen and Christensen 2003; Diffenbaugh et al. 2005; Duffy et al. 2003), higher resolution climate models also require rigorous evaluation.

To that end, our goal is to assess the ability of a highresolution nested climate model (RegCM3; Pal et al. 2007) to capture the statistics of daily-scale temperature and precipitation events over the conterminous United States, and to understand the dynamical sources of mismatch between the model simulation and observational and reanalysis data. Although those statistics do not necessarily provide insight into the dynamics of sub-daily, local-scale severe weather events (e.g. Trapp et al. 2007a), they are important for understanding the impacts of climate variability and change (e.g. Parry et al. 2007; Solomon et al. 2007).

\section{Methods}

\subsection{High-resolution climate model}

We employ the Abdus Salam International Centre for Theoretical Physics (ICTP) regional climate model (RegCM3) (Pal et al. 2007). RegCM3 is a 3-dimensional, primitive equation, nested climate model. In order to test the effects of varying horizontal resolution on RegCM3's ability to capture the statistics of daily-scale temperature and precipitation events, we apply the model at both $55-\mathrm{km}$ horizontal gridspacing ("Reg55"; using the grid of Diffenbaugh et al (2006a), Pal et al. (2000) and at 25-km horizontal gridspacing ("Reg25"; using the grid of Diffenbaugh et al.
(2005). Both grids are centered over the conterminous United States, with 18 levels in the vertical. We perform one simulation with each grid, following the physics options of Pal et al. (2000) in both cases. Lateral boundary conditions for both simulations are provided by NCEP-DOE reanalysis data (R2) (Kanamitsu et al. 2002). Both simulations cover the period 1982-2002, with the first year discarded to account for model equilibration.

\subsection{High-resolution reanalysis}

We validate the RegCM3 performance against the NCEP North American Regional Reanalysis (NARR) (Mesinger et al. 2006). NARR is a long-term, high-resolution climate dataset for North America, with data available from 1979 through the present. NARR has horizontal resolution of $32 \mathrm{~km}$, with 29 levels in the vertical. Developed as a regional improvement on the NCEP/NCAR Global Reanalysis (R1) (Kalnay et al. 1996), NARR includes many advances in data assimilation-including daily precipitation observations - which are expected to result in an accurate representation of extreme events (Mesinger et al. 2006). As with the global reanalysis, $2 \mathrm{~m}$ temperature observations are not directly assimilated (Mesinger et al. 2006). NARR is unique for our purposes in that it allows for comparisons of sub-daily, 3-dimensional atmospheric and surface fields at a horizontal resolution similar to that of our RegCM3 grids.

\subsection{Precipitation observations}

We compare daily-scale precipitation in both RegCM3 and NARR with the $0.25^{\circ} \mathrm{NCEP} / \mathrm{NOAA}$ gridded daily precipitation data [NCEP]. Precipitation data sources included in the dataset are the River Forecast Center and the Climate Anomaly Data Base. The number of reliable gauge stations included in the dataset is maximized from 1998-present [NCEP]. Therefore, we use the years 1998-2002 for comparison with the climate model simulations.

\subsection{Statistics of daily-scale temperature and precipitation distributions}

We analyze the long-term annual statistics of 95th percentile daily maximum temperature (T95), 5th percentile daily minimum temperature (T05), and 95th percentile daily precipitation (P95) at each grid point, following Diffenbaugh (2005, 2006b), Diffenbaugh et al. (2005). Each of these metrics is first calculated for each year of the timeseries, with the values from each year averaged to create the long-term mean statistic at each grid point. For the temperature metrics, there is one daily maximum and one daily minimum recorded for each day of the year. 
Thus, for each year, the 95th percentile daily maximum temperature can be taken as the 18th hottest daily maximum of the year, while the 5 th percentile daily minimum temperature can be taken as the 18th coldest daily minimum of the year. For T95 (T05), we first identify the 18th hottest (coldest) day of each year at each grid point. For each gridpoint, we then calculate the mean of all of the yearly T95 (T05) values, yielding the mean threshold value across all of the years in the timeseries.

Alternatively, precipitation will not necessarily occur at each grid point in each day of the year. Thus, for the P95 metric, we must first determine whether a precipitation day has occurred. As in Diffenbaugh et al. (2005) and Diffenbaugh (2005), we follow Salinger and Griffiths (2001) in defining a "rain day" as a day in which precipitation exceeds $1.0 \mathrm{~mm}$. Then, for each year, we rank the rain days by magnitude at each grid point, and identify the 95th percentile rain day from the respective ranked lists. We then calculate the mean of all of the yearly 95th percentile values at each grid point, yielding the mean threshold value across all of the years in the timeseries. In addition to P95, we record the annual number of rain days (NRD) at each grid point. Further, we calculate the sum annual precipitation (SAP) at each grid point as the mean of the total precipitation that falls during rain days in each year, and the precipitation event average (PEA) as SAP divided by NRD at each grid point.

For each of these variables, we analyze the mean, interannual standard deviation, and linear trend across the years of the time series at each grid point. In order to calculate quantitative differences between fields from RegCM3 and NARR, RegCM3 data are regridded from their original grid to the NARR grid. Differences are then taken as RegCM3 minus NARR for each grid point in each of the RegCM3 simulations (Reg55 and Reg25). It should be noted that, given the difference in horizontal resolution between the different grids, some information can be lost in the regridding. Specifically, the information on the $25-\mathrm{km}$ RegCM3 grid will be somewhat smoothed when interpolated to the $32-\mathrm{km}$ NARR grid. This smoothing could spuriously affect the calculated differences, particularly in areas of high spatial variability such as the western United States.

\section{Results}

\subsection{Seasonal means, 1983-2002}

Both Reg25 and Reg55 capture the pattern of seasonal temperature and precipitation seen in the NARR dataset (Figs. 1, 2). Key temperature biases include overly warm December-January-February (DJF) temperatures over the northern Great Plains in both Reg25 and Reg55, overly cool March-April-May (MAM) and September-OctoberNovember (SON) temperatures over lower elevation areas of the Mountain West in Reg25 and Reg55, and overly warm June-July-August (JJA) temperatures over the southern Great Plains in Reg55 (Fig. 1). Reg25 improves the agreement of seasonal temperature with NARR
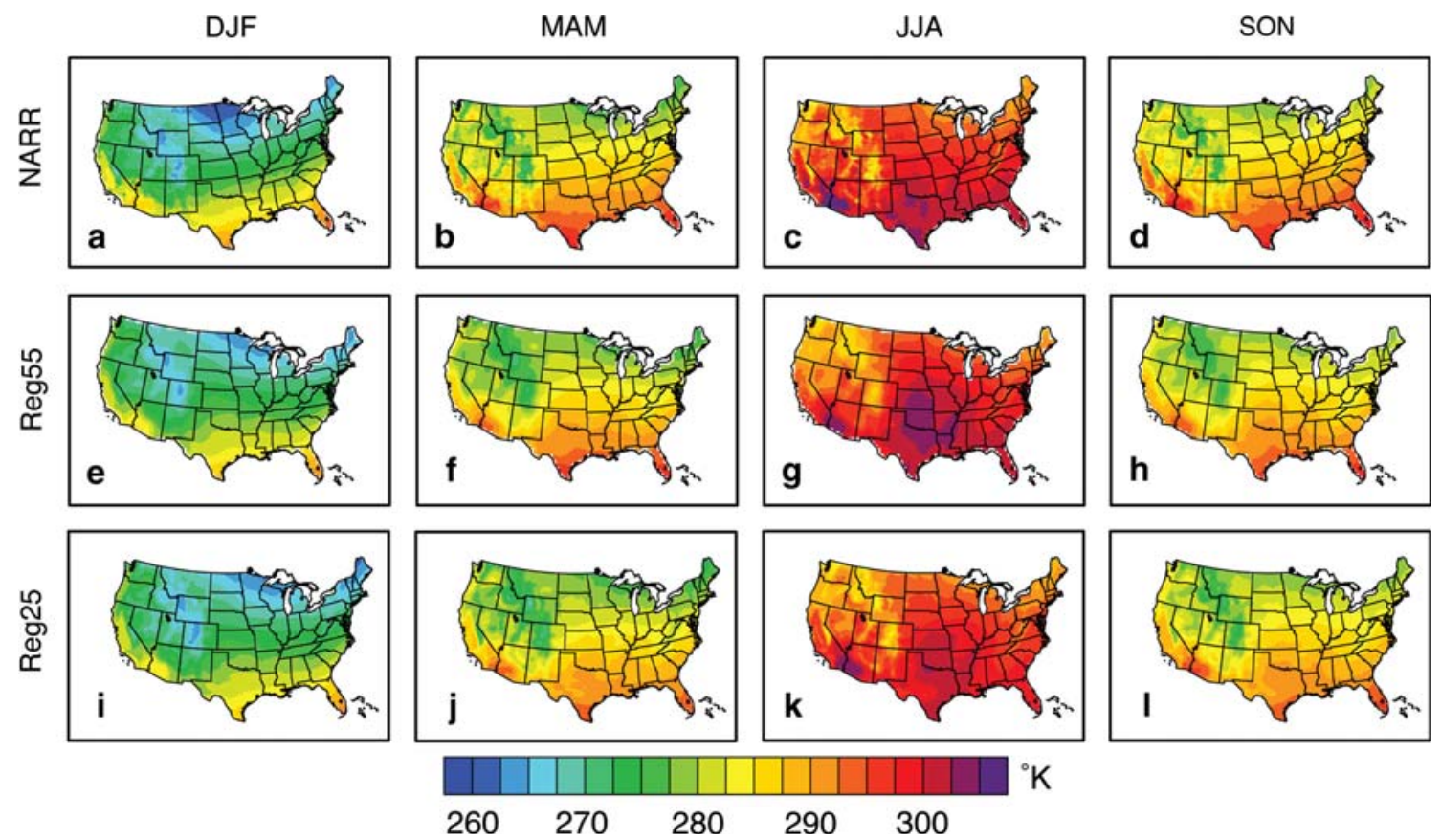

Fig. 1 Mean seasonal surface air temperature, 1983-2002. a-d NARR. e-h Reg55. i-l Reg25 

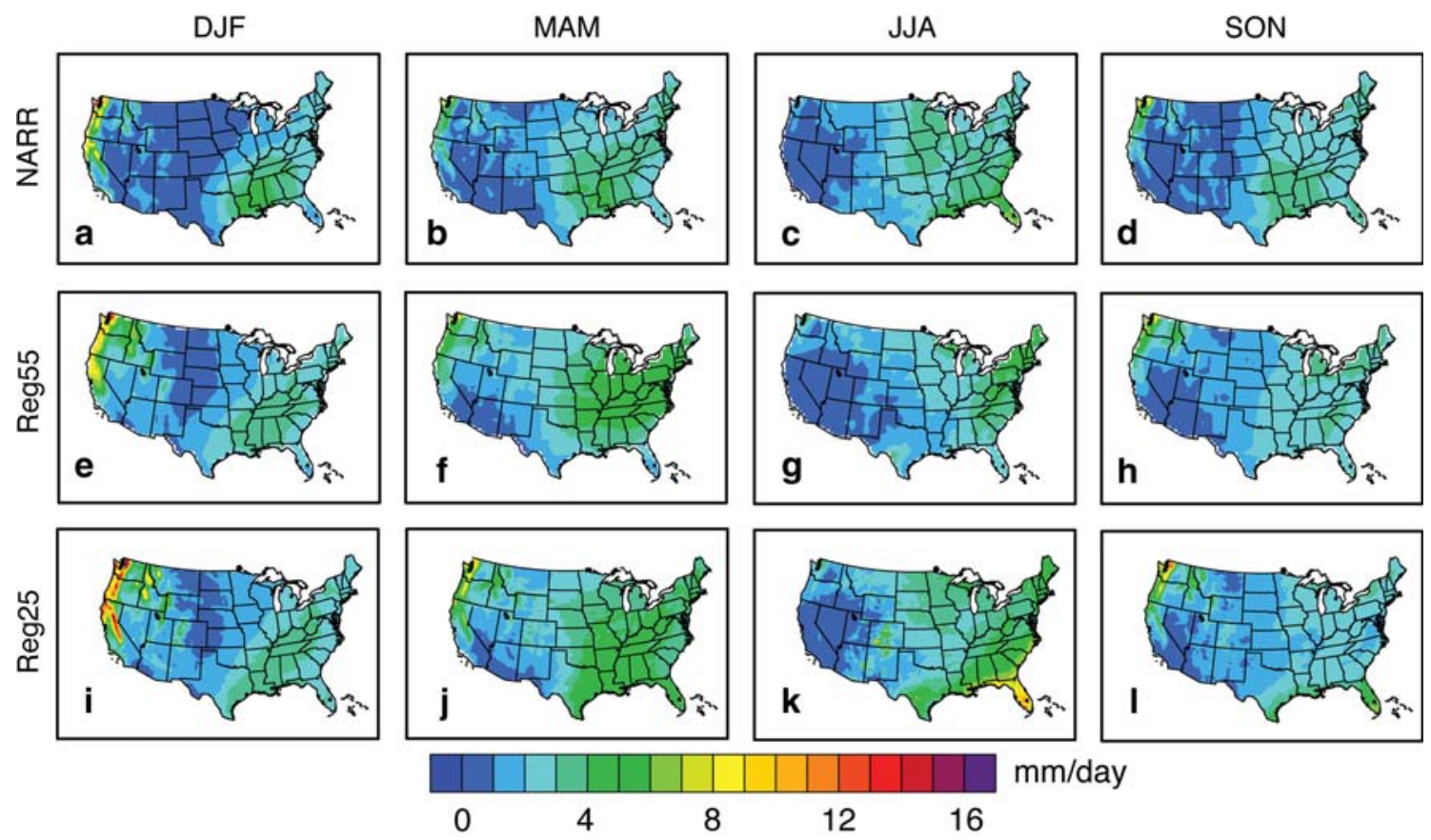

Fig. 2 As in Fig. 1, but for precipitation

Fig. 3 Annual 5th percentile minimum temperatures, 19832002. a, d, g 20-year mean, standard deviation, and linear trend for NARR. b, e, h 20-year mean, standard deviation, and linear trend for Reg55. c, f, i 20year mean, standard deviation, and linear trend for Reg25
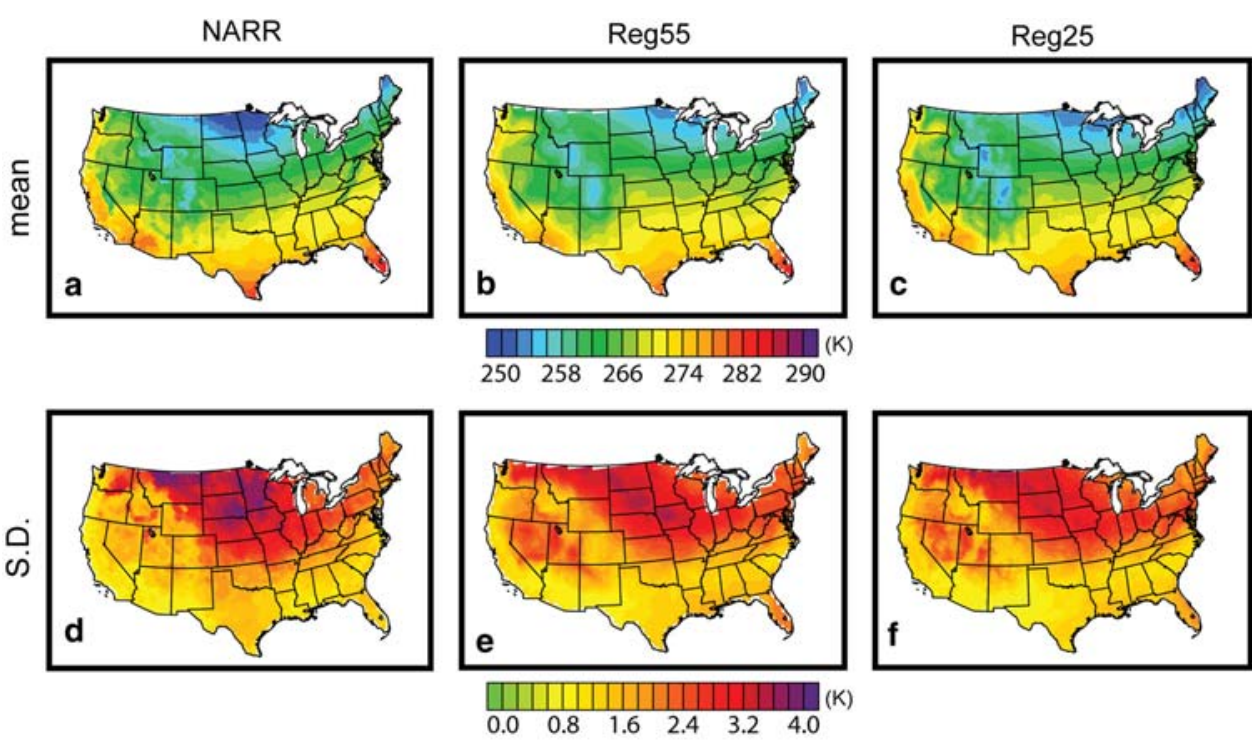

$\begin{array}{llllll}0.0 & 0.8 & 1.6 & 2.4 & 3.2 & 4.0\end{array}$
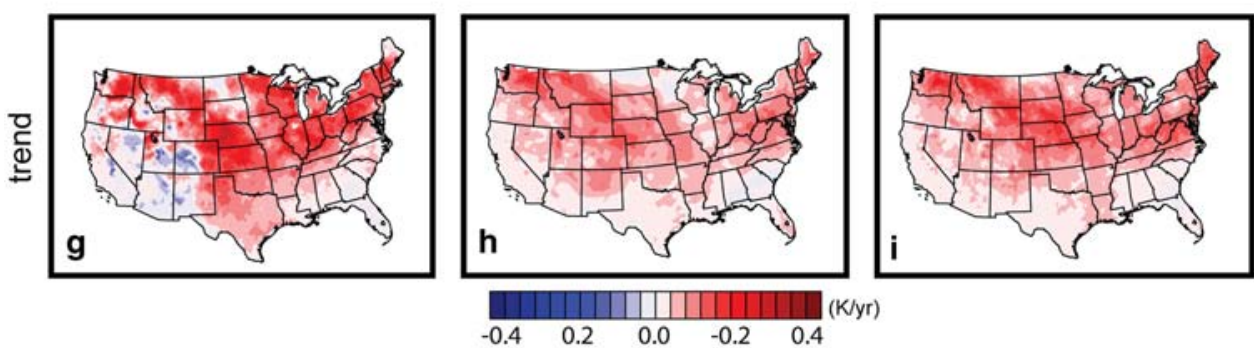

(relative to Reg55) over the southern Great Plains in JJA, and over the topographically complex Mountain West in MAM, JJA and SON.
Key precipitation biases include overly wet DJF precipitation over high elevation areas of the Mountain West in Reg25, overly dry MAM, JJA, and SON precipitation 


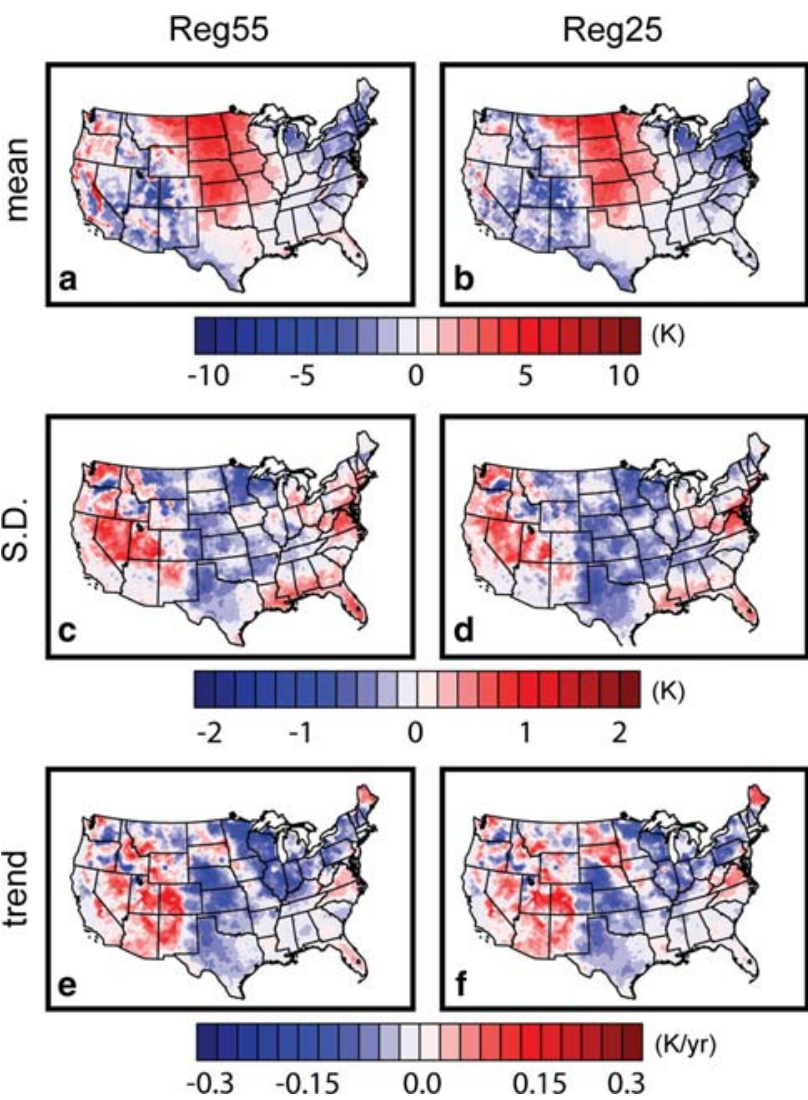

Fig. 4 Biases in annual 5th percentile minimum temperatures, 19832002. a, c, e Differences in 20-year mean, standard deviation, and linear trend between Reg55 and NARR. b, d, f Differences in 20-year mean, standard deviation, and linear trend between Reg25 and NARR. Differences are calculated as RegCM3-NARR at each gridpoint

along the Gulf Coast in Reg55, and overly wet JJA precipitation over parts of the Mountain West and along the Gulf Coast in Reg25 (Fig. 2). Reg25 improves the agreement of seasonal precipitation with NARR (relative to Reg55) over the Midwest in JJA. In addition, Reg25 improves the spatial structure of seasonal precipitation over the topographically complex Mountain West in DJF, MAM and SON.

\subsection{T05, 1983-2002}

The spatial patterns of T05 means, standard deviations, and trends are largely consistent between RegCM3 and NARR (Fig. 3), with coldest temperatures and greatest interannual variability occurring in the northern interior of the domain. In NARR, the coldest mean T05 values of less than $-20^{\circ} \mathrm{C}$ occur in North Dakota and Minnesota, while the warmest values of greater than $10^{\circ} \mathrm{C}$ occur in southern Florida and southern Texas. T05 temperatures are generally too warm in the northern Great Plains and too cold in the Northeast,
Southwest and Mountain West (Fig. 4). In the Midwest (Northeast), RegCM3-simulated values are too warm (too cold) by as much as $5^{\circ} \mathrm{C}$.

In the central United States, RegCM3 produces too little interannual variation in the cold tail of the daily temperature distribution, with biases in the standard deviation of T05 ranging from -0.5 to $-1{ }^{\circ} \mathrm{C}$ (Fig. 3). Similarly, RegCM3-simulated T05 temperatures are also too variable by up to $1^{\circ} \mathrm{C}$ in the eastern and western portions of the U.S. RegCM 3 captures the spatial pattern of T05 trends, with strong positive trends of up to $0.15^{\circ} \mathrm{C} /$ year stretching from the Pacific Northwest south and eastward to the Great Plains, along with strong positive trends from the Great Lakes region to New England (Fig. 3). Although RegCM3 captures the spatial distribution of trends, it tends to underestimate the strongest trends (by as much as $-0.2^{\circ} \mathrm{C} /$ year in the midsection of the country), and misses slight negative trends of -0.05 to $-0.1^{\circ} \mathrm{C} /$ year across the Desert Southwest (Fig. 3).

\subsection{T95, 1983-2002}

Maximum T95 values of $42^{\circ} \mathrm{C}$ in NARR occur in the southern Great Plains, in southern Arizona, and in the interior of California. RegCM3 captures the general pattern of T95 means, with highest T95 values occurring across the southern Great Plains and Desert Southwest, where T95 values range from 40 to $45^{\circ} \mathrm{C}$ in $\operatorname{Reg} 25$ and Reg55. Both resolutions display a warm bias of up to $7^{\circ} \mathrm{C}$ across the Southeast and Midwest, and a cold bias in the Central Valley of California (Figs. 5, 6). The area of warm T95 bias over the south and central U.S. is reduced in Reg25 relative to Reg55, as is the magnitude of the bias (from 7 to $5^{\circ} \mathrm{C}$ ) (Fig. 6).

Both Reg55 and Reg25 capture maxima in T95 interannual variability across the eastern Great Plains and western Midwest (Fig. 5), but substantially overestimate the magnitude and spatial extent of that area of maximum variability. This overestimation is most pronounced in Reg55 across the eastern Midwest, and in Reg25 across southern Texas and the northern Great Plains (Fig. 6). The largest Reg25 variability biases correspond to areas that are designated as crop in the RegCM3 land cover boundary condition (not shown).

Reg25 captures the basic pattern of positive trends in T95 across the western U.S., Great Plains, and East Coast (up to $0.1{ }^{\circ} \mathrm{C} /$ year), and negative trends across Minnesota, North Dakota, and the Midwest (maximum negative trends of $-0.2^{\circ} \mathrm{C}$ year) (Fig. 5). However, Reg25 overestimates the negative trends across the Midwest by as much as $50 \%$, and extends the area of negative T95 trends too far south and east. Although Reg55 captures the slight negative trends of -0.05 to $0.1^{\circ} \mathrm{C} /$ year across Minnesota and North 
Fig. 5 As in Fig. 3, but for annual 95th percentile maximum temperatures
Dakota, it shows strong positive trends in T95 of up to $0.3^{\circ} \mathrm{C} /$ year across the central and eastern portion of the country. These trends are not found in either NARR or Reg25. This bias toward strongly positive T95 trends in Reg55 corresponds to the areas of greatest bias in T95 means and T95 standard deviations (Fig. 6).

\subsection{Aggregate precipitation variables, 1983-2002}

NARR displays broadly consistent spatial patterns in mean SAP, NRD, and PEA (Fig. 7). The highest mean values generally occur in the high elevations of the Mountain West, in the southeastern and southcentral U.S., and in the Northeast, with peak values in the Northeast most prominent for NRD and SAP (Fig. 7). Wet biases in the RegCM3 simulation of PEA occur over most of the domain, with the exception of the Gulf Coast region in Reg55 and the central Plains and Appalachian Mountains in Reg25 (Figs. 7, 8). RegCM3 also overestimates SAP and NRD in the Northeast, northern Great Plains, and especially in the higher elevations of the Mountain West. Conversely, RegCM3 underestimates both SAP and NRD in the southeastern and southcentral U.S., which, coupled with its relatively accurate simulation of the average event magnitude (PEA), suggests that biases in annual rainfall (SAP) over these regions are likely caused by an insufficient number of
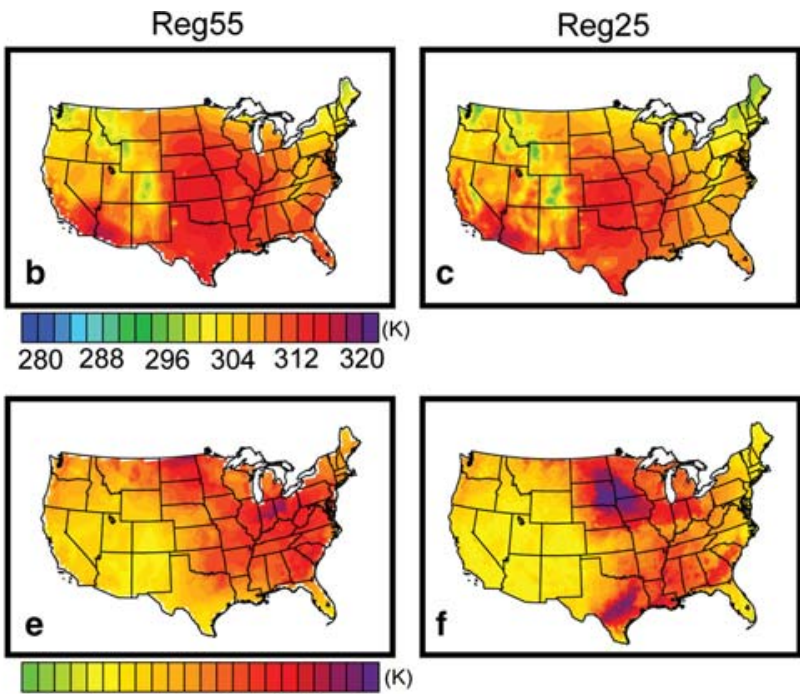

$\begin{array}{llllll}0.0 & 0.8 & 1.6 & 2.4 & 3.2 & 4.0\end{array}$
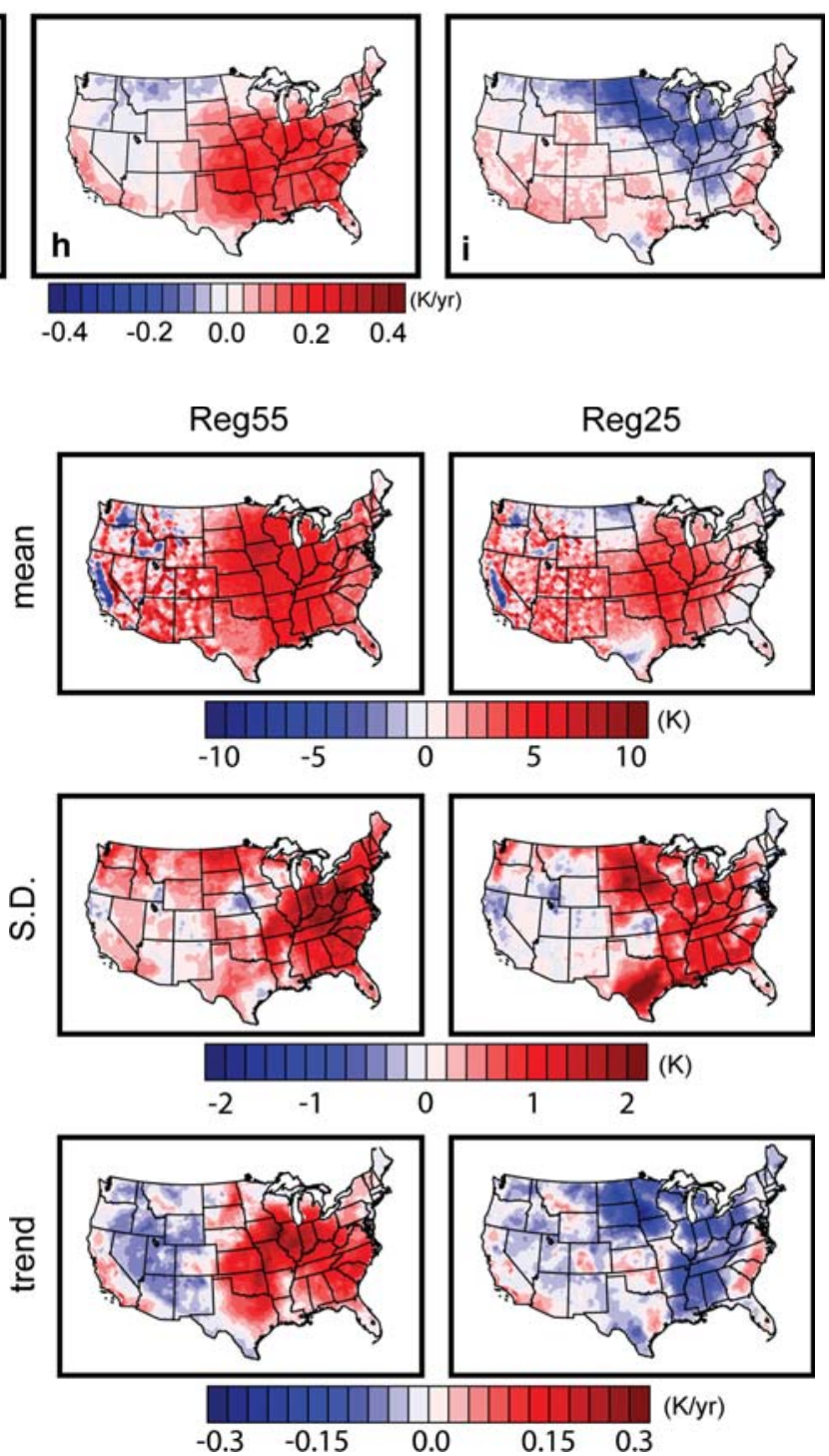

Fig. 6 As in Fig. 4, but for annual 95th percentile maximum temperatures 
Fig. 7 20-year means of annual precipitation variables, 19832002. a, b, c 95th percentile annual precipitation event (P95) for NARR, Reg55, and Reg25, respectively. d, e, f Sum of annual precipitation (SAP) for NARR, Reg55, and Reg25, number of days with rain greater than $1 \mathrm{~mm} /$ day (NRD) for NARR, Reg55, and Reg25, average rainfall per rain day (PEA) for NARR, Reg55, and Reg25, respectively respectively. g, h, i Annual respectively. j, k, l Annual
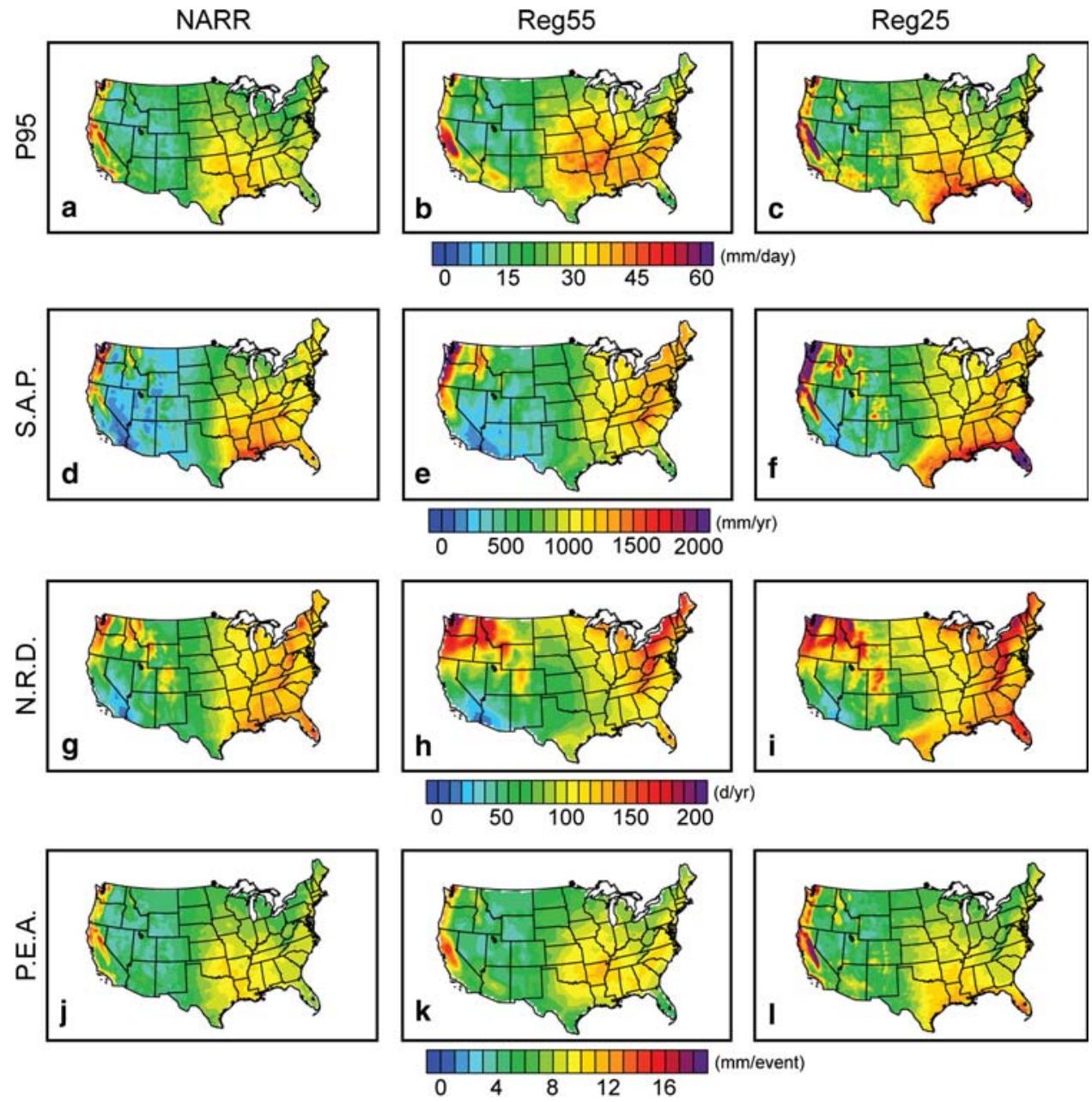

rainfall events rather than insufficient rainfall during individual rainfall events.

Regions with high mean SAP, NRD, and PEA in NARR (Fig. 7) also tend to have high interannual variability in those variables (Fig. 9). The highest variability in SAP and PEA occurs along the Pacific coast, in the higher elevations of the Rocky Mountains, and in the southeastern and southcentral U.S. (Fig. 9). NRD variability is high throughout the western and southeastern U.S. (Fig. 9). Spatial patterns in interannual variability are broadly consistent between NARR, Reg55, and Reg25, with the exception of an overestimation of variability in Reg25 along the Gulf Coast for all three variables (Fig. 9).

Negative trends in SAP, NRD, and PEA are evident in the western U.S. in NARR, and are especially pronounced in the Southwest (Fig. 10). Negative trends in the number of rain days in the Southeast are accompanied by somewhat weaker negative trends in SAP. As a result, PEA shows positive trends throughout much of the eastern U.S. (Fig. 10). Positive trends in SAP, NRD, and PEA also occur over the northern Great Plains and upper Midwest (Fig. 10). RegCM3 correctly identifies the general spatial distribution of these trends, although Reg55 overestimates the spatial extent of negative NRD trends in the West and the strength of negative NRD trends in the Southeast (where Reg55 also overestimates the strength of negative SAP trends) (Fig. 10).

\subsection{P95, 1983-2002}

NARR shows two areas of peak P95 values (Fig. 7). The first spans Louisiana, western Mississippi, southern Arkansas, and eastern Oklahoma, where maximum values reach $35-40 \mathrm{~mm} /$ day. The second spans the high elevations of the Pacific coast, where P95 values range from 50 to $60 \mathrm{~mm} /$ day. Minimum values are found in the Mountain West and southwestern U.S.

RegCM3 captures this spatial pattern of heavy precipitation across the conterminous United States, with highest P95 values occurring in the Southeast, the Gulf Coast, and throughout the high elevations of the Mountain West (Fig. 7). In Reg55, the area of maximum P95 values is expanded and shifted northward relative to that seen in NARR, while in Reg25, the area of maximum P95 values is concentrated along the Gulf Coast. Both Reg55 and Reg25 

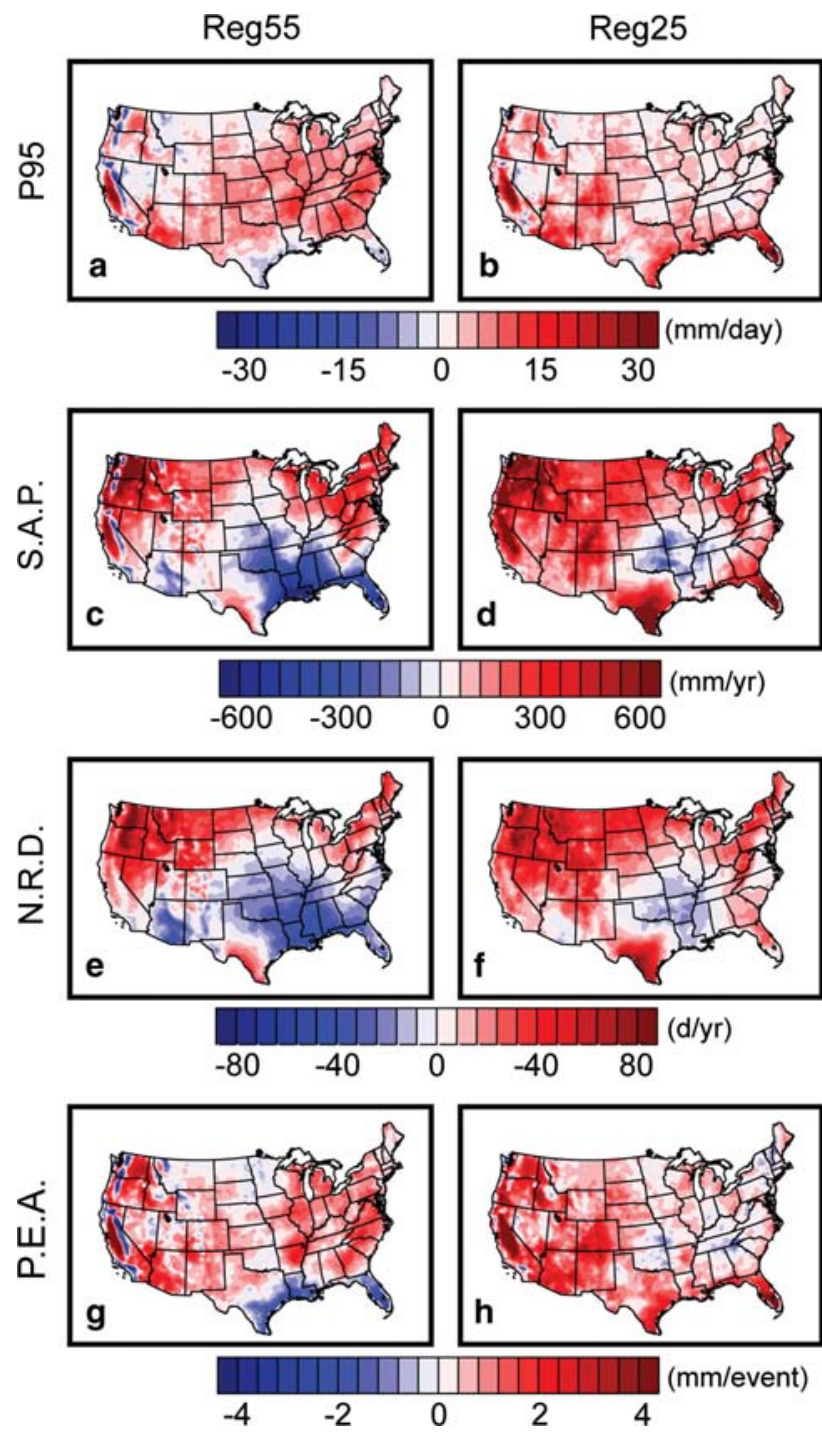

Fig. 8 Biases in mean annual precipitation variables, 1983-2002. a, c, e, $\mathbf{g}$ Differences in P95, SAP, NRD, and PEA between Reg55 and NARR. b, d, f, h Differences in P95, SAP, NRD, and PEA between Reg25 and NARR. Differences are calculated as RegCM3-NARR at each gridpoint

capture the intense precipitation along the Cascade and Sierra Nevada mountain ranges, with Reg25 more accurately resolving the $\mathrm{P} 95$ peaks on either side of California's Central Valley.

Reg55 and Reg25 do overestimate maximum values of P95 in some areas (Fig. 8). For example, the maximum P95 values over the Southeast are $35-40 \mathrm{~mm} /$ day in NARR, while they are as high as $45 \mathrm{~mm} /$ day (in Arkansas and eastern Oklahoma) in Reg55 and as high as $60 \mathrm{~mm} /$ day (in southern Florida) in Reg25. Biases of 5-15 mm/day occur across the eastern United States in Reg55, while biases of 15$30 \mathrm{~mm} /$ day occur along the Gulf Coast in Reg25 (Fig. 8). Biases are generally reduced over the central and eastern U.S. in Reg25 relative to Reg55. Dry biases in the Mountain
West are also reduced in Reg25, although Reg25 is still too wet in some low-elevation regions, such as California's Central Valley (where biases reach 50-100\%). Comparison with precipitation observations (Fig. 11) reveals that NARR underestimates the magnitude and spatial extent of maximum P95 means in the southeastern U.S. Reg55 most accurately captures this pattern of P95 mean values, with maximum values of 45-55 mm/day extending from eastern Texas northward through Oklahoma, eastward through Kentucky, and southward through Alabama.

The spatial pattern of the interannual standard deviation of P95 in NARR is broadly consistent with the pattern of the mean values (Figs. 7, 9). Maximum P95 variability occurs in the high elevations of California, along with parts of the southeast and southcentral U.S. Although Reg25 and Reg55 capture the basic pattern, both overestimate P95 variability in the southeastern and southcentral U.S. As with the mean precipitation values, Reg55 and Reg25 show greater agreement with the precipitation observations than does NARR over many areas of the domain (Fig. 12).

RegCM3 is also able to capture the basic pattern of trends in the wet tail of the daily precipitation distribution (Fig. 10). Both Reg55 and Reg25 capture positive trends in P95 magnitude across the central and eastern regions of the U.S., and negative trends in P95 magnitude in parts of the West. RegCM3 simulates areas of strong negative trends in southern California and southwestern Texas that appear to correspond with similar features in NARR. RegCM3 also simulates positive trends along coastal Washington, Oregon, and California, as well as in much of the Midwest.

\subsection{RMS errors}

Although Reg25 appears to display an enhanced ability to capture the spatial patterns of means, trends, and interannual variability of daily-scale statistics relative to Reg55, examination of spatial RMS errors reveals that Reg25 does not always quantitatively outperform Reg55. Reg25 does show reduced RMS errors relative to Reg55 in all regions of the country for T95, while RMS errors for T05 are similar for both Reg25 and Reg55 (Table 1). However, RMS errors in precipitation are consistently higher in Reg25 than in Reg55 for all regions except the Southeast. In most of these regions, RMS errors in precipitation are dominated by wet biases that are particularly prominent in the higher resolution simulation (Fig. 8).

\section{Discussion}

\subsection{Western United States}

Areas of the western U.S. are subject to soil moisture deficits that are strongest during the winter season over the 
Fig. 9 As in Fig. 7, but for interannual standard deviations of annual precipitation variables
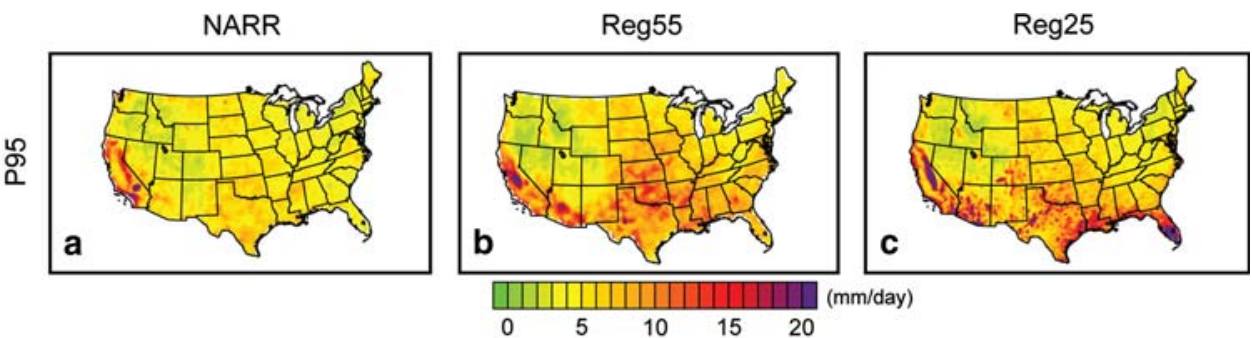

Reg55
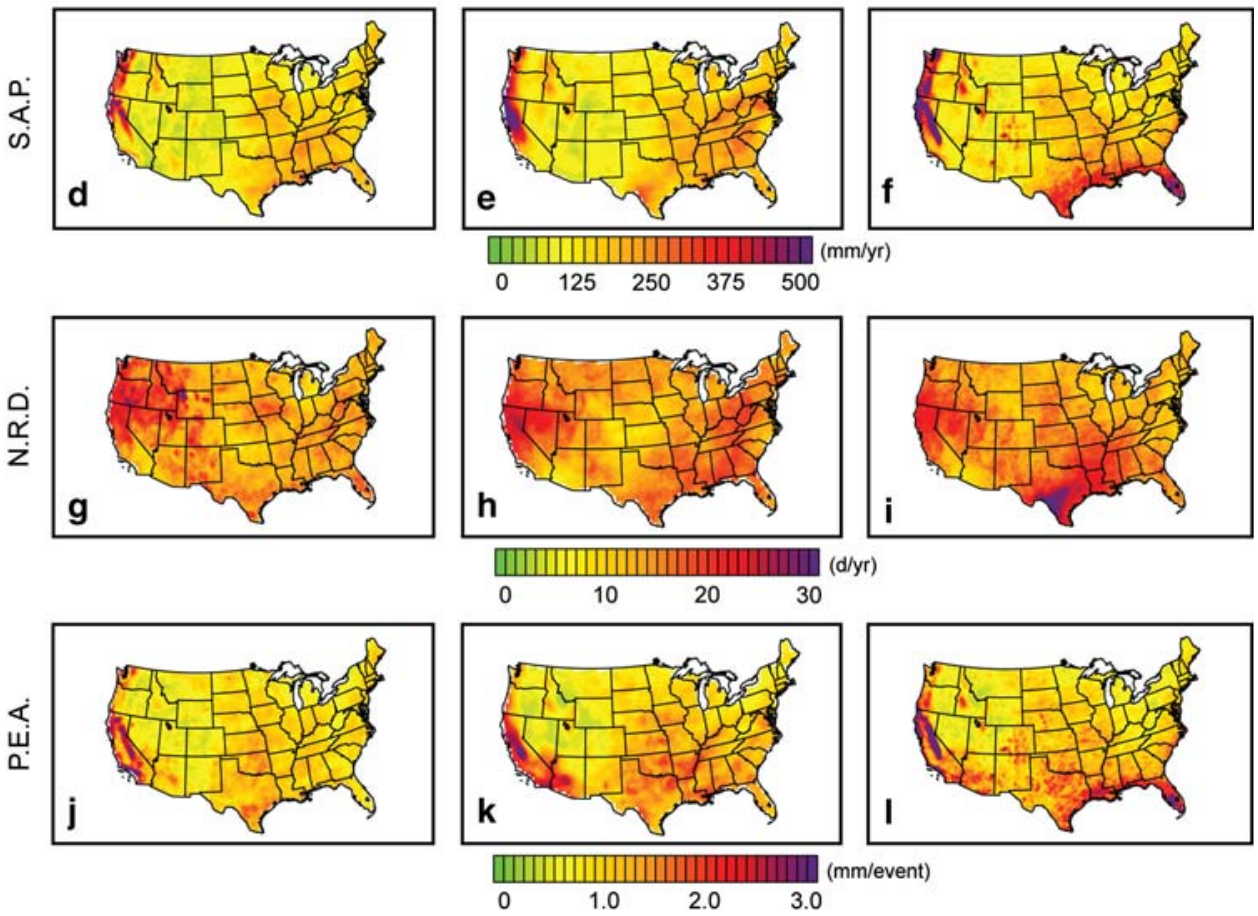

highest elevations of Colorado and Wyoming, and of greatest spatial extent during the summer and fall (Fig. 13). These same regions also experience deficits in latent heat flux, with greatest bias occurring during the spring and summer over the Rocky Mountains and during the fall over the Desert Southwest (Fig. 14). These negative biases in soil moisture and latent heat flux occur despite positive biases in SAP and NRD over much of the western U.S. (Fig. 8). Although absolute biases in precipitation are larger for Reg25 than for $\operatorname{Reg} 55$, Reg25 displays some reduction in soil moisture and latent heat flux biases over these regions.

In both RegCM3 simulations, warm T95 biases are found in the Mountain West, particularly at high elevations (Fig. 6). These T95 biases at high elevations are coincident with negative biases in soil moisture and latent heat flux, and with positive biases in precipitation. Warm temperature biases accompanying deficits in soil moisture and latent heat flux indicate that more surface heating is being converted to sensible heat rather than latent heat, resulting in elevated T95 temperatures during the warm season. The simultaneous occurrence of excess precipitation with soil moisture deficits could indicate improper treatment of runoff and infiltration in RegCM3.

During the winter, the trough which is centered over the Midwest in NARR is deepened and shifted westward in RegCM3 (Fig. 15), resulting in winds over the Rocky Mountains that are too strong out of the Northwest (Fig. 16). This region of enhanced wintertime northwesterly flow divides T05 biases in the western U.S., with cool biases to the west of the mountains and warm biases to the east of the mountains (Fig. 4). During the summer, the corridor of southerly winds seen in NARR over the southern Plains is shifted westward in Reg55 as a result of a north and westward shift of anticyclonic circulation off of the Atlantic coast (Fig. 15). A similar shift is found in Reg25, although the displacement in the center of circulation is substantially smaller.

Although the absolute differences in precipitation in mountainous regions are larger in Reg25 than in Reg55, the spatial structure of precipitation is better resolved in the higher resolution simulation (Fig. 7). This trade-off between spatial structure and absolute errors is likely the result of enhanced orographic forcing in the $25 \mathrm{~km}$ 
Fig. 10 As in Fig. 8, but for linear trends of annual precipitation variables
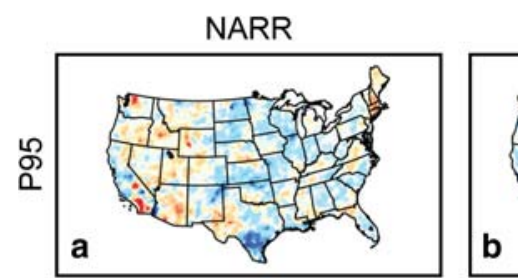

Reg55
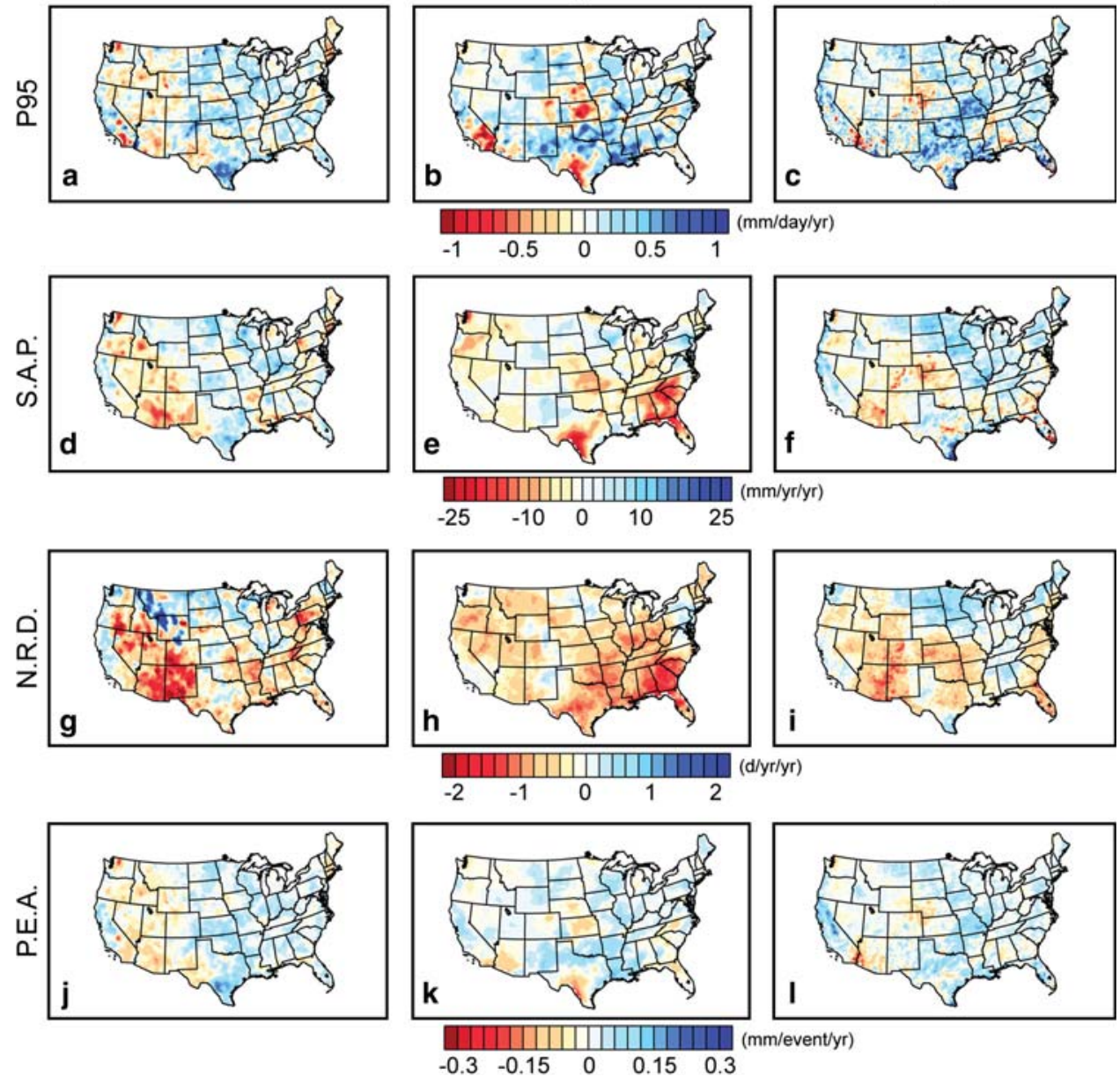

simulation. Wind velocities are generally too strong across these regions in both simulations (Fig. 16). However, Reg25 has more highly-resolved topography (and therefore higher peak elevations) due to its higher horizontal resolution, which could be expected to interact with the strong winds to cause stronger orographic effects and therefore enhanced precipitation over topographic peaks (Fig. 7).

\subsection{Eastern United States}

RegCM3 temperature and precipitation biases in the eastern United States are dominated by warm-season dynamics. During the spring and summer seasons, large deficits in both soil moisture and latent heat flux develop in the southeastern and southcentral U.S. (Figs. 13, 14, respectively). These are regions that also experience substantial deficits in annual precipitation in the RegCM3 simulations (Fig. 8c, d), and are subject to large positive T95 biases (Fig. 6a, b). These biases are of highest magnitude and largest spatial extent in the Reg55 simulation.

A partial explanation for these biases is derived from errors in the RegCM3 circulation patterns. During the warm season, strong southerly and southeasterly winds bring moisture from the Gulf of Mexico into the southern Plains and the Southeast, where this moisture is a crucial element in the development of the convective thunderstorms that provide a substantial portion of annual precipitation to these regions (Fig. 15). However, the misplacement of anticyclonic circulation off of the Atlantic coast in RegCM3 alters circulation both at the surface (Fig. 15) and throughout the lower- and mid-troposphere (not shown), resulting in insufficient southerly winds over the Gulf of Mexico (Figs. 15, 16).

For example, in Reg55, circulation over the Gulf of Mexico is due easterly, precluding sufficient moisture transport to the southeastern U.S. and southern Great Plains. The resulting lack of rainfall (Fig. 8c, d, e, and f) leads to soil moisture deficits over these regions (Fig. 13), where biases in soil moisture coincide with biases in SAP and NRD. Without sufficiently moist soils, and with reduced southerly winds, evapotranspiration over these areas is also reduced, resulting in negative latent heat flux biases and strong warm biases in daily maximum temperatures (Fig. 6). Conversely, the Reg25 simulation exhibits 
Fig. 11 5-year means of annual precipitation variables, 19982002. a, b, c, d 95th percentile annual precipitation event (P95) for precipitation observations, NARR, Reg55, and Reg25, respectively. e, f, $\mathbf{g}, \mathbf{h}$ Sum of annual precipitation (SAP) for precipitation observations, NARR, Reg55, and Reg25, respectively. i, j, k, l Annual number of days with rain greater than $1 \mathrm{~mm} /$ day (NRD) for precipitation observations, NARR, Reg55, and Reg25, respectively. $\mathbf{m}, \mathbf{n}, \mathbf{o}, \mathbf{p}$ Annual average rainfall per rain day (PEA) for precipitation observations, NARR, Reg55, and $\operatorname{Reg} 25$, respectively
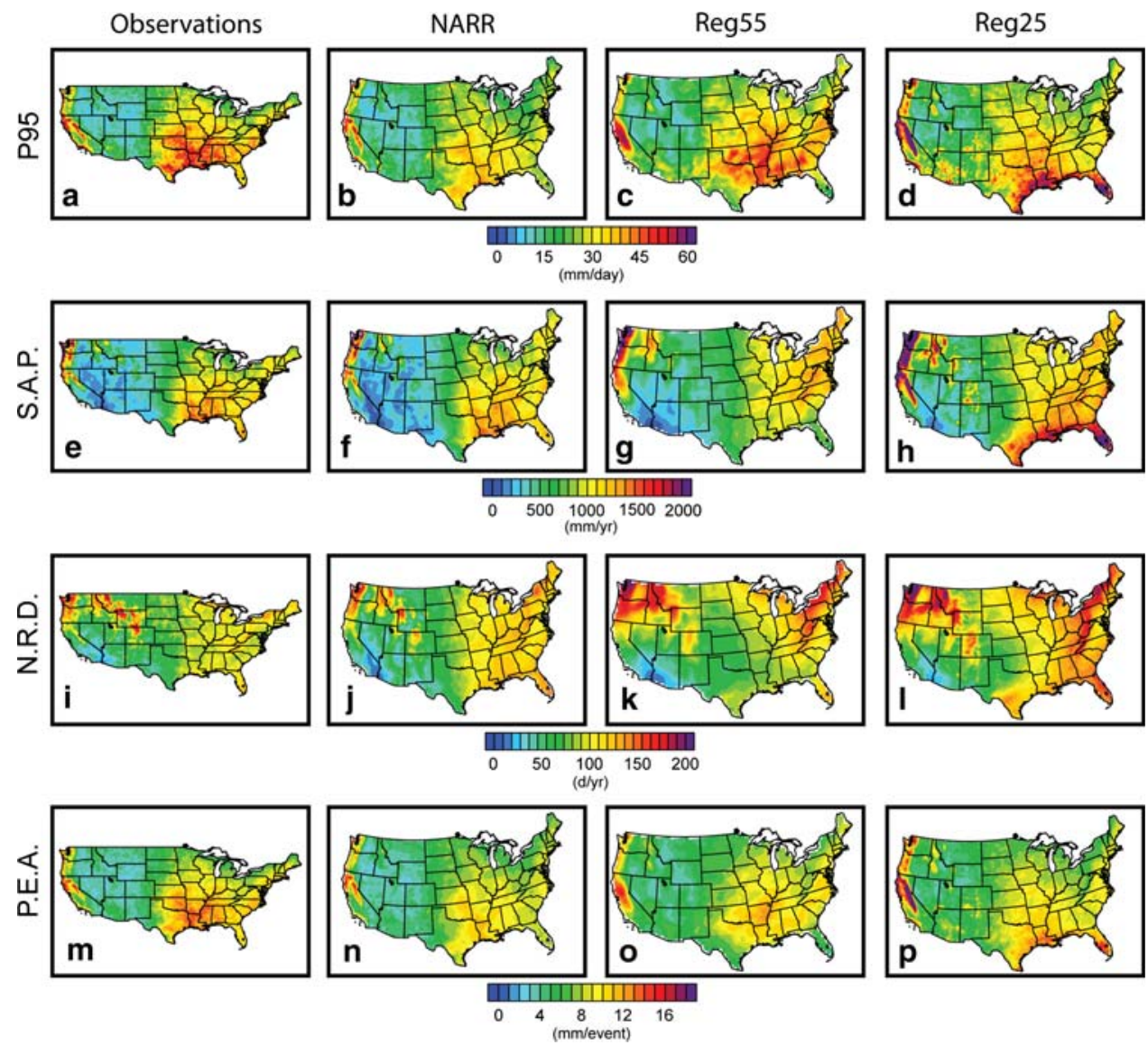

only a small bias in the placement of anticyclonic circulation off of the Atlantic coast (Fig. 15), with reduced biases in total precipitation (Fig. 8), surface moisture fields (Figs. 13, 14), and T95 (Fig. 6).

Differences in the representation of land-atmosphere interactions in RegCM3 and NARR could also contribute to the hotter, drier summer conditions simulated by RegCM3 in the southeastern and southcentral U.S. Although the land cover designations are broadly similar between RegCM3 and NARR (not shown), RegCM3 and NARR utilize different land models and different vegetation parameter values (Mesinger et al. 2006; Pal et al. 2007). These differences in land surface parameterization could contribute to the soil moisture differences between RegCM3 and NARR. Variations in soil moisture have been shown to exert a strong influence on both precipitation (Koster et al. 2004) and temperature (Seneviratne et al. 2006) variability, including in the Great Plains and along the Gulf Coast of the U.S. (Koster et al. 2004). Exclusive of any circulation bias, a deficit in soil moisture could itself produce hot and dry biases such as those seen in our simulations. In addition, such soil moisture anomalies could themselves influence the large-scale circulation (e.g. Pal and Eltahir 2003).

\section{Conclusions}

RegCM3 captures the spatial patterns of extreme temperature and precipitation events over the conterminous U.S. Although the long-term means of the daily-scale statistics are most accurately represented, RegCM3 generally captures the spatial pattern of interannual variability and linear trends, particularly at higher horizontal resolution (Figs. 3, $5,10)$. Regions of notable bias include the topographicallycomplex western U.S., the Southeast, and the Midwest. Precipitation biases in areas of complex topography are associated with overly strong winds, which create errors in orographically-driven precipitation. Likewise, biases in simulated temperature and precipitation metrics in the southeastern and southcentral U.S. are at least partially driven by biases in circulation and moisture fields. These dynamical biases are generally larger in the lower-resolution simulation.

Our work has potentially important implications for the broader study of climate and climate change. First, our work suggests that nested high-resolution climate models can accurately capture the statistics of daily-scale temperature and precipitation. Changes in the tails of the dailyscale distribution can have far greater impact than changes 

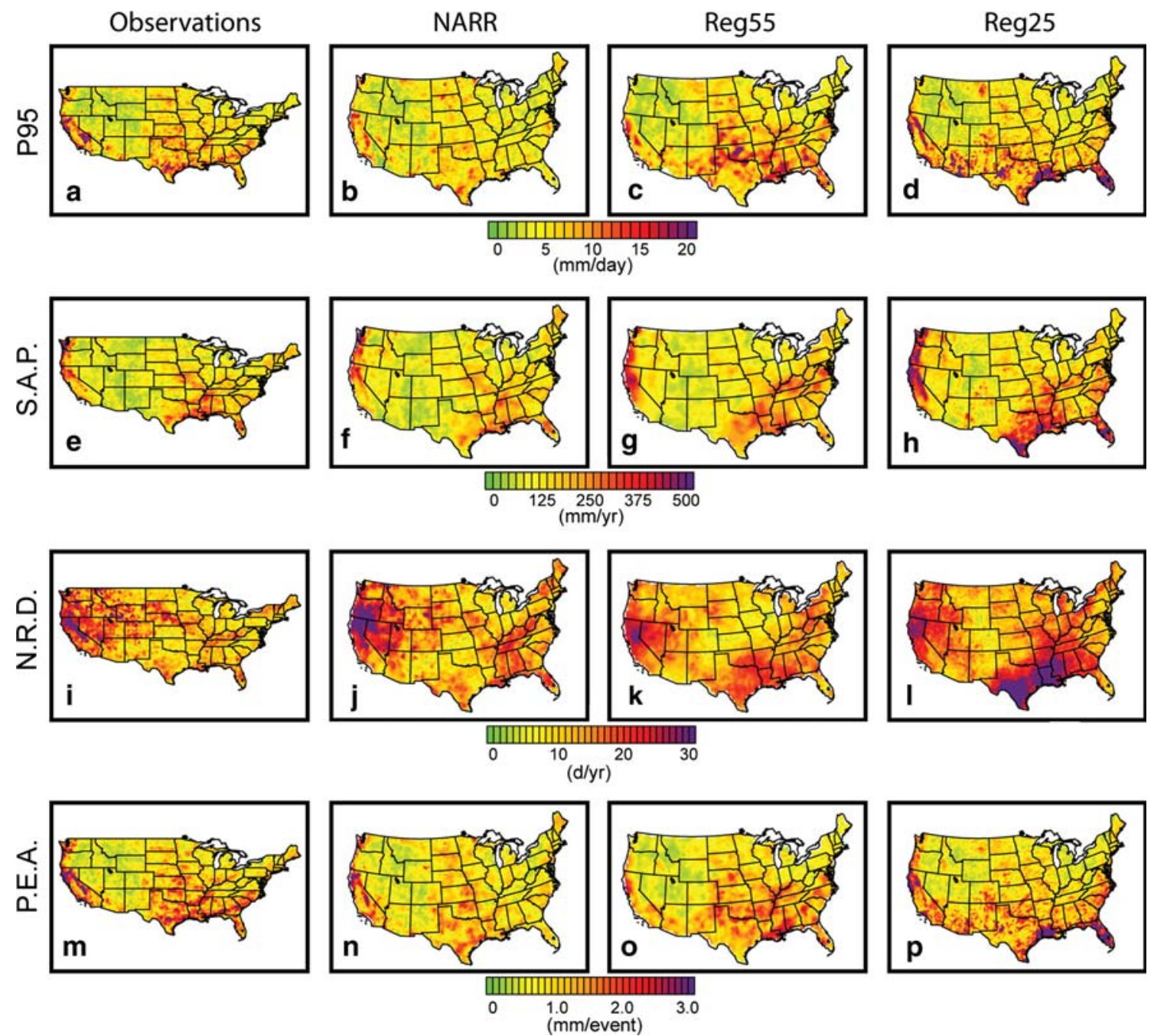

Fig. 12 As in Fig. 11, but for interannual standard deviations of annual precipitation variables

in the seasonal-scale mean (e.g. Parry et al. 2007; White et al. 2006). Quantifying the reliability (and limitations) of complex climate models in simulating the tails of the temperature and precipitation distribution is therefore important as the community moves from evaluating the sensitivity of long-term, global- and large-scale climate to evaluating the sensitivity of daily- and local-scale climate that is critical for accurately assessing the impacts of climate variability and change on natural and human systems (e.g. Christensen et al. 2007; Giorgi et al. 2008; Parry et al. 2007).

Second, our work suggests that, for the tails of the daily temperature and precipitation distributions, the areas of agreement and disagreement with the observational data are not always intuitive from analyzing the mean seasonal temperature and precipitation fields alone. For instance, the warm T95 bias over the central U.S. in Reg25 (Fig. 5) is not clear when analyzing mean summer temperature
(Fig. 1), and the cool summer bias over the Southeast in Reg25 (Fig. 1) does not confer a cool bias in mean T95 magnitude (Fig. 5). Likewise, the Reg25 and Reg55 P95 wet biases over southern Arizona are larger than indicated by any of the respective seasonal precipitation fields, as is the Reg55 P95 wet bias over the Sierra Nevada (Fig. 7).

Third, our work suggests that relatively subtle errors in the simulation of atmospheric circulation and surface energy and moisture fluxes can produce relatively large errors in the simulations of the statistics of daily-scale temperature and precipitation. This error cascade is illustrated by the case of T95 biases over the southcentral U.S., where errors in the atmospheric circulation over the Gulf of Mexico in Reg55 create large warm biases over the central U.S. The fact that Reg25 exhibits more accurate atmospheric circulation over the Gulf of Mexico and reduction in the T95 biases over the central U.S. suggests that higher resolution could confer more accurate simulation of the tails 
Table 1 Regional root mean squared (RMS) error (compared with NARR fields)

\begin{tabular}{|c|c|c|c|c|c|c|c|}
\hline \multirow[t]{2}{*}{ Variable } & \multirow[t]{2}{*}{ Simulation } & \multicolumn{6}{|l|}{ Region } \\
\hline & & Northwest & Northcentral & Northeast & Southwest & Southcentral & Southeast \\
\hline \multirow[t]{2}{*}{ T95 mean } & Reg55 & 4.42 & 3.84 & 3.86 & 3.70 & 4.95 & 4.19 \\
\hline & Reg25 & 4.05 & 2.75 & 1.83 & 3.16 & 3.29 & 2.29 \\
\hline \multirow[t]{2}{*}{ T05 mean } & Reg55 & 2.12 & 1.42 & 1.51 & 2.09 & 2.90 & 2.00 \\
\hline & Reg25 & 1.96 & 1.48 & 1.49 & 1.93 & 2.68 & 2.64 \\
\hline \multirow[t]{2}{*}{ P95 mean } & Reg55 & 9.98 & 5.73 & 8.69 & 7.89 & 5.85 & 8.23 \\
\hline & $\operatorname{Reg} 25$ & 11.69 & 8.00 & 16.91 & 9.31 & 4.98 & 4.83 \\
\hline \multirow[t]{2}{*}{ SAP mean } & Reg55 & 105.11 & 229.63 & 325.53 & 368.85 & 142.96 & 253.42 \\
\hline & Reg25 & 146.89 & 307.13 & 415.52 & 466.27 & 235.30 & 205.22 \\
\hline \multirow[t]{2}{*}{ NRD mean } & Reg55 & 18.14 & 22.82 & 33.64 & 40.45 & 21.10 & 18.48 \\
\hline & Reg25 & 11.94 & 26.71 & 17.38 & 43.72 & 27.13 & 19.77 \\
\hline \multirow[t]{2}{*}{ PEA mean } & Reg55 & 1.83 & 0.93 & 1.32 & 1.84 & 0.83 & 1.389 \\
\hline & Reg25 & 2.21 & 1.48 & 2.58 & 2.30 & 1.02 & 1.02 \\
\hline
\end{tabular}

Fig. 13 Seasonal mean soil water fraction for the top $10 \mathrm{~cm}$ of soil, 1983-2002. Left column shows values from NARR. Center column shows values from Reg55 minus NARR. Right column shows values from Reg25 minus NARR. a, b, c DJF; d, e, f MAM; $\mathbf{g}, \mathbf{h}, \mathbf{i}$; JJA; $\mathbf{j}, \mathbf{k}, \mathbf{l}$ SON
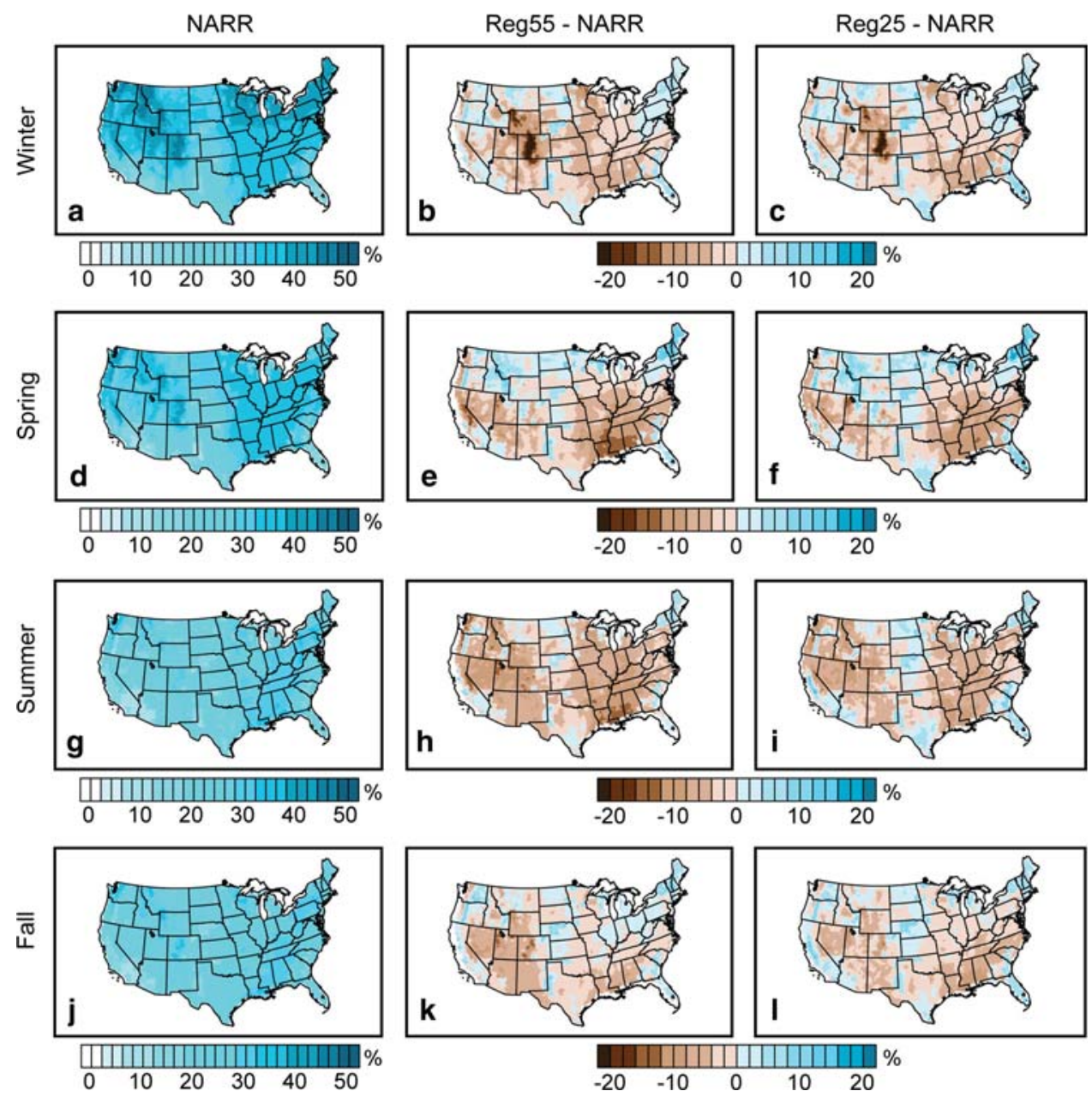

of the daily-scale distribution. In addition, the sensitivity to regional-scale atmospheric features in these historical simulations also implies that the statistics of daily-scale temperature and precipitation could be likewise sensitive to relatively subtle changes in circulation induced by changes in radiative forcing of the climate system. 

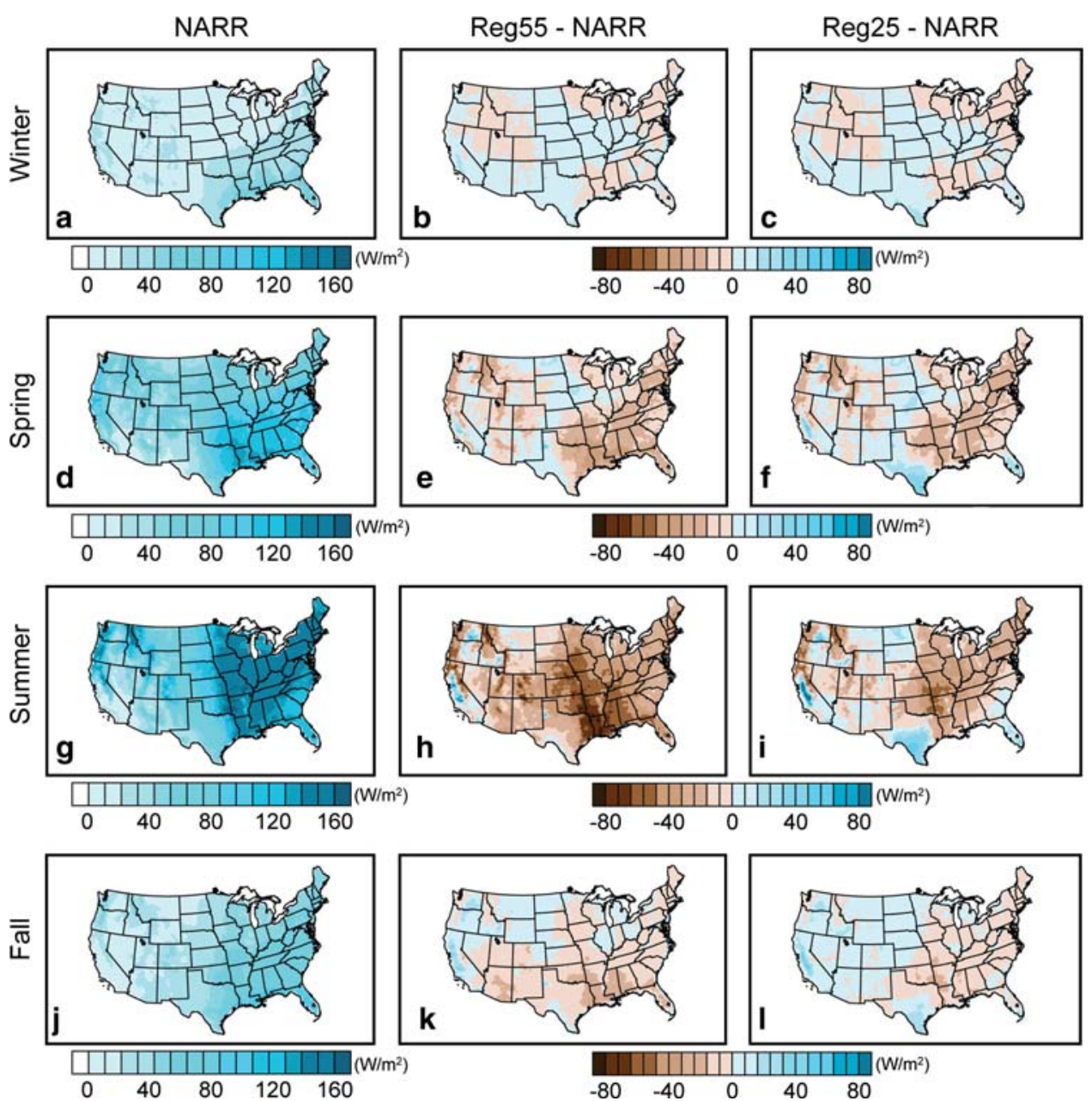

Fig. 14 As in Fig. 13, but for seasonal latent heat flux
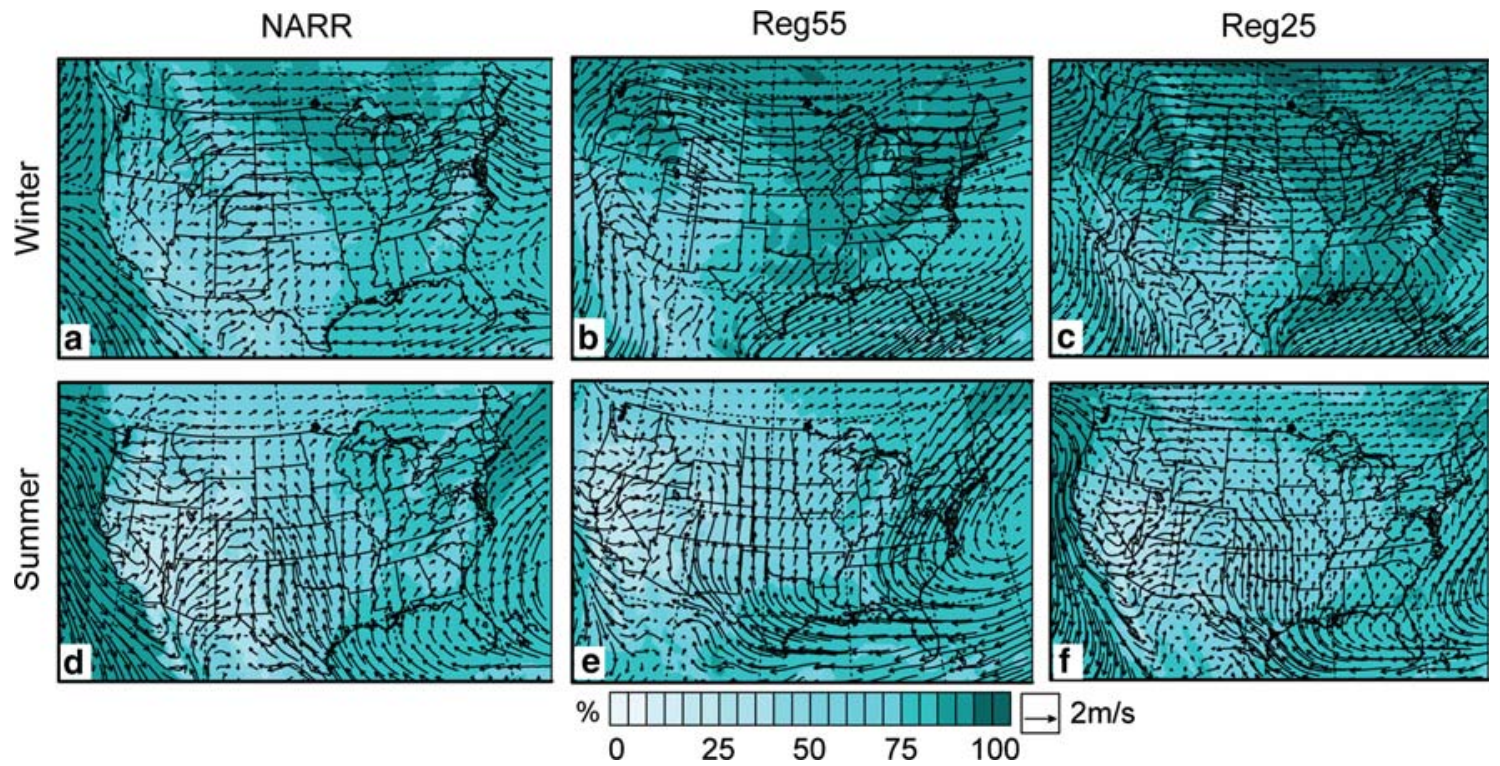

Fig. 15 Seasonal surface zonal and meridional winds and relative humidity, 1983-2002. a, b, c DJF horizontal surface winds and relative humidity for NARR, Reg55, and Reg25, respectively. d, e, f JJA horizontal surface winds and relative humidity for NARR, Reg55, and Reg25, respectively 

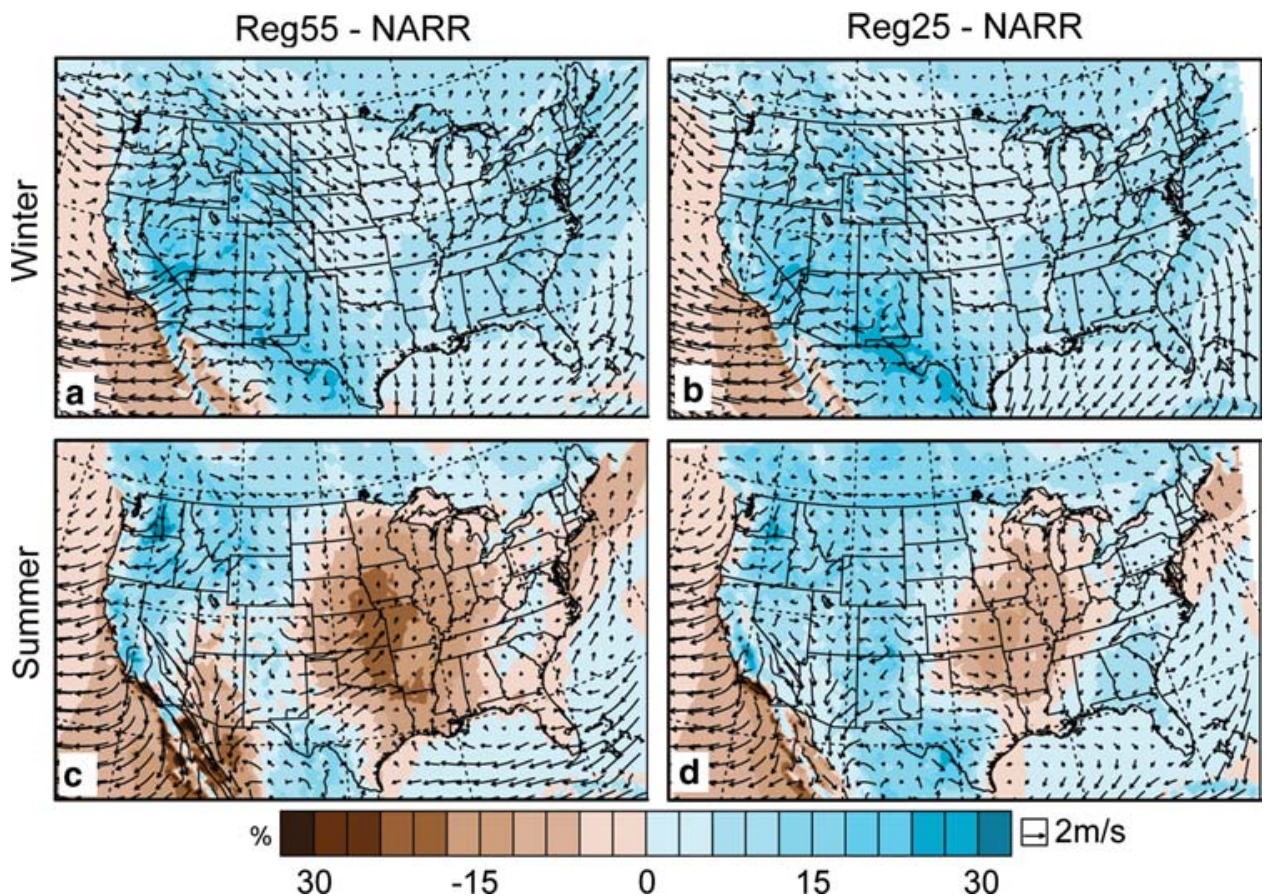

Fig. 16 Biases in seasonal surface zonal and meridional winds and relative humidity, seasonal analyses, 1983-2002. a, b DJF differences in surface horizontal winds and relative humidity for Reg55 minus

Although our work offers insight into the ability of a nested high-resolution climate model to capture the statistics of daily-scale temperature and precipitation events, some limitations remain. First, RegCM3 was forced by reanalysis data, representing the "best case scenario" for model performance. To fully assess the ability of RCMs to simulate future changes in extreme climate events, validation should also be performed for RCMs driven by GCM output over historical periods for which highquality observational data are available. Second, although we have explored the effect of increased horizontal resolution on the simulation of daily-scale temperature and precipitation events, the model performance could also be improved through increases in vertical resolution (e.g. Todd et al. 2008). Third, we focus here on the simulation of the statistics of daily-scale temperature and precipitation. The ability to capture these statistics does not necessarily confer the ability to accurately simulate specific extreme temperature and precipitation events (e.g. Trapp et al. 2007b).

Acknowledgements We thank M. Ashfaq, K.R. Gurney and R.J. Trapp for helpful discussions, and one anonymous reviewer for insightful and constructive comments. The climate model simulations were generated using resources in the Rosen Center for Advanced Computing (RCAC), which is supported by Information Technology at Purdue (ITaP). NCEP Reanalysis data were provided by the NOAA/OAR/ESRL PSD, Boulder, Colorado, USA, from their website at http://www.cdc.noaa.gov/. This work was supported by NSF
NARR and Reg25 minus NARR, respectively. c, d JJA differences in surface horizontal winds and relative humidity for Reg55 minus NARR and Reg25 minus NARR, respectively

Awards 0541491 and 0450221, and DOE Award DE-FG0208ER64649. This is PCCRC paper number 0917.

Open Access This article is distributed under the terms of the Creative Commons Attribution Noncommercial License which permits any noncommercial use, distribution, and reproduction in any medium, provided the original author(s) and source are credited.

\section{References}

Bell JL et al (2004) Regional changes in extreme climatic events: a future climate scenario. J Clim 17:81-87. doi:10.1175/15200442(2004)017<0081:RCIECE $>2.0 . C O ; 2$

Brody SD et al (2007) The rising costs of floods-examining the impact of planning and development decisions on property damage in Florida. J Am Plann Assoc 73:330-345. doi:10.1080/ 01944360708977981

Christensen JH, Christensen OB (2003) Climate modelling: severe summertime flooding in Europe. Nature 421:805-806. doi: $10.1038 / 421805 \mathrm{a}$

Christensen JH et al (2007) Regional climate projections. In: Solomon $S$ et al (eds) Climate change 2007: the physical science basis. Contribution of working group I to the fourth assessment report of the intergovernmental panel on climate change. Cambridge

Christidis N, Stott PA, Brown S, Hegerl GC, Caesar J (2005) Detection of changes in temperature extremes during the second half of the 20th century. Geophys Res Lett 32, L20716. doi: 10.1029/2005GL023885

DeGaetano AT, Allen RJ (2002) Trends in twentieth-century temperature extremes across the United States. J Clim 15:3188-3205. doi: 10.1175/1520-0442(2002)015<3188:TITCTE $>2.0 . C O ; 2$ 
Diffenbaugh NS (2005) Sensitivity of extreme climate events to $\mathrm{CO}_{2}$ induced biophysical atmosphere-vegetation feedbacks in the western United States. Geophys Res Lett 32:L07702. doi: 07710.01029/02004GL022184

Diffenbaugh NS et al (2005) Fine-scale processes regulate the response of extreme events to global climate change. Proc Natl Acad Sci USA 102:15774-15778. doi:10.1073/pnas.0506042102

Diffenbaugh NS, Ashfaq M, Shuman B, Williams JW, Bartlein PJ (2006a) Summer aridity in the United States: response to midHolocene changes in insolation and sea surface temperature. Geophys Res Lett 33, L22712. doi:10.1029/2006GL028012

Diffenbaugh NS et al (2006b) Simulated changes in extreme temperature and precipitation events at $6 \mathrm{ka}$. Palaeogeogr Palaeoclimatol Palaeoecol 236:151-168. doi:10.1016/j.palaeo. 2005.11.037

Diffenbaugh NS et al (2007) Heat stress intensification in the Mediterranean climate change hotspot. Geophys Res Lett 34

Duffy PB et al (2003) High-resolution simulations of global climate, part 1: present climate. Clim Dyn 21:371-390. doi:10.1007/ s00382-003-0339-Z

Easterling DR et al (1999) Long-term observations for monitoring extremes in the Americas. Clim Change 42:285-308. doi: 10.1023/A: 1005484820026

Easterling DR et al (2000) Climate extremes: observations, modeling, and impacts. Science 289:2068-2074. doi:10.1126/science. 289.5487.2068

Ferris R et al (1998) Effect of high temperature stress at anthesis on grain yield and biomass of field-grown crops of wheat. Ann Bot (Lond) 82:631-639. doi:10.1006/anbo.1998.0740

Giorgi $\mathrm{F}$ et al (2008) The regional climate change hyper-matrix framework. Eos 89:445-446. doi:10.1029/2008EO450001

Gosling SN et al (2007) Climate change and heat-related mortality in six cities Part 1: model construction and validation. Int $\mathrm{J}$ Biometeorol 51:525-540. doi:10.1007/s00484-007-0092-9

Groisman PY et al (2005) Trends in intense precipitation in the climate record. J Clim 18:1326-1350. doi:10.1175/JCLI3339.1

Hall A, Qu X, Neelin JD (2008) Improving predictions of summer climate change in the United States. Geophys Res Lett 35, L01702. doi:10.1029/2007GL032012

Hegerl GC et al (2006) Climate change detection and attribution: beyond mean temperature signals. J Clim 19:5058-5077. doi: 10.1175/JCLI3900.1

Huth R et al (2000) A GCM simulation of heat waves, dry spells, and their relationships to circulation. Clim Change 46:29-60. doi: 10.1023/A: 1005633925903

IPCC WGI (2007) Climate change 2007: the physical science basis: contribution of working group I to the fourth assessment report of the intergovernmental panel on climate change

Kalnay E et al (1996) The NCEP/NCAR 40-year reanalysis project. Bull Am Meteorol Soc 77:437-471. doi:10.1175/1520-0477 (1996)077<0437:TNYRP>2.0.CO;2

Kanamitsu M et al (2002) NCEP-DOE AMIP-II reanalysis (R-2). Bull Am Meteorol Soc 83:1631-1643. doi:10.1175/BAMS-83-111631(2002)083<1631:NAR $>2.3 . \mathrm{CO} ; 2$

Karl TR, Knight RW (1998) Secular trends of precipitation amount, frequency, and intensity in the United States. Bull Am Meteorol Soc 79:231-241. doi:10.1175/1520-0477(1998)079<0231: STOPAF $>2.0 . \mathrm{CO} ; 2$

Katz RW, Brown BG (1992) Extreme events in a changing climatevariability is more important than averages. Clim Change 21:289-302. doi:10.1007/BF00139728

Kharin VV, Zwiers FW (2000) Changes in the extremes in an ensemble of transient climate simulations with a coupled atmosphere-ocean GCM. J Clim 13:3760-3788. doi:10.1175/ 1520-0442(2000)013<3760:CITEIA $>2.0$. CO $; 2$
Koffi B, Koffi E (2008) Heat waves across Europe by the end of the 21st century: multiregional climate simulations. Clim Res 36:153-168

Koster RD et al (2004) Regions of strong coupling between soil moisture and precipitation. Science 305:1138-1140. doi: 10.1126/science. 1100217

Kunkel KE et al (1999) Temporal fluctuations in weather and climate extremes that cause economic and human health impacts: a review. Bull Am Meteorol Soc 80:1077-1098. doi:10.1175/ 1520-0477(1999)080<1077:TFIWAC $>2.0 . C O ; 2$

Kysely J (2002) Comparison of extremes in GCM-simulated, downscaled and observed central-European temperature series. Clim Res 20:211-222. doi:10.3354/cr020211

Lobell DB (2007) Changes in diurnal temperature range and national cereal yields. Agric For Meteorol 145:229-238. doi:10.1016/ j.agrformet.2007.05.002

Mearns LO et al (1984) Extreme high-temperature events-changes in their probabilities with changes in mean temperature. J Clim Appl Meteorol 23:1601-1613. doi:10.1175/1520-0450(1984) $023<1601$ :EHTECI $>2.0 . \mathrm{CO} ; 2$

Meehl GA et al (2000) An introduction to trends in extreme weather and climate events: observations, socioeconomic impacts, terrestrial ecological impacts, and model projections. Bull Am Meteorol Soc 81:413-416. doi:10.1175/1520-0477(2000) 081<0413:AITTIE $>2.3 . \mathrm{CO} ; 2$

Meehl GA, Arblaster JM, Tebaldi C (2005) Understanding future patterns of increased precipitation intensity in climate model simulations. Geophys Res Lett 32, L18719. doi:10.1029/ 2005GL023680

Mesinger F et al (2006) North American regional reanalysis. Bull Am Meteorol Soc 87:343. NCEP, C. Realtime Daily U.S. Precipitation Analysis. doi:10.1175/BAMS-87-3-343

Pal JS, Eltahir EAB (2003) A feedback mechanism between soilmoisture distribution and storm tracks. Q J R Meteorol Soc 129:2279-2297. doi:10.1256/qj.01.201

Pal JS et al (2000) Simulation of regional-scale water and energy budgets: representation of subgrid cloud and precipitation processes within RegCM. J Geophys Res Atmospheres 105: 29579-29594. doi:10.1029/2000JD900415

$\mathrm{Pal}$ JS et al (2007) Regional climate modeling for the developing world-the ICTP RegCM3 and RegCNET. Bull Am Meteorol Soc 88:1395. doi:10.1175/BAMS-88-9-1395

Parry ML et al (2007) IPCC, 2007: climate change 2007: impacts, adaptation and vulnerability. Contribution of working group II to the fourth assessment report of the intergovernmental panel on climate change. Cambridge University Press, Cambridge, $976 \mathrm{pp}$

Penning-Rowsell E, Wilson T (2006) Gauging the impact of natural hazards: the pattern and cost of emergency response during flood events. Trans Inst $\mathrm{Br}$ Geogr 31:99-115. doi:10.1111/j. 1475-5661.2006.00200.x

Poumadere $\mathrm{M}$ et al (2005) The 2003 heat wave in France: dangerous climate change here and now. Risk Anal 25:1483-1494. doi: 10.1111/j.1539-6924.2005.00694.x

Salinger MJ, Griffiths GM (2001) Trends in New Zealand daily temperature and rainfall extremes. Int J Climatol 21:1437-1452. doi:10.1002/joc. 694

Schar C et al (2004) The role of increasing temperature variability in European summer heatwaves. Nature 427:332-336. doi: 10.1038 /nature 02300

Seneviratne SI et al (2006) Land-atmosphere coupling and climate change in Europe. Nature 443:205-209. doi:10.1038/nature05095

Smoyer-Tomic KE et al (2003) Heat wave hazards: an overview of heat wave impacts in Canada. Nat Hazards 28:463-485. doi: 10.1023/A:1022946528157 
Solomon S et al (2007) IPCC, 2007: climate change 2007: the physical science basis. contribution of working group I to the fourth assessment report of the intergovernmental panel on climate change 996 pp. Cambridge University Press, Cambridge

Todd MC et al (2008) Regional model simulations of the Bodele low-level jet of northern Chad during the Bodele Dust Experiment (BoDEx 2005). J Clim 21:995-1012. doi:10.1175/ 2007JCLI1766.1

Trapp RJ et al (2007b) Telescoping, multi-model approaches to evaluate extreme convective weather under future climates. J Geophys Res Atmos. doi:10.1029/2006JD008345

Trapp RJ et al (2007) Changes in severe thunderstorm environment frequency during the 21 st century caused by anthropogenically enhanced global radiative forcing. Proc Natl Acad Sci USA 104:19719-19723. doi:10.1073/pnas.0705494104

Trenberth KE (1999) Conceptual framework for changes of extremes of the hydrological cycle with climate change. Clim Change 42:327-339. doi:10.1023/A:1005488920935

Wehner MF (2004) Predicted twenty-first-century changes in seasonal extreme precipitation events in the parallel climate model. J Clim 17:4281-4290. doi:10.1175/JCLI3197.1

White MA et al (2006) Extreme heat reduces and shifts United States premium wine production in the 21st century. Proc Natl Acad Sci USA 103:11217-11222. doi:10.1073/pnas.0603230103 